\title{
La idealización del amor y la mujer en La vorágine
}

\section{The idealization of love and woman in The Vortex}

\section{Carlos Daniel Ortiz Caraballo*}

\section{Resumen}

El trabajo a realizar es un análisis sociocrítico de La vorágine (1924), de José Eustasio Rivera (Neiva, 1888-Nueva York, 1928). Su objetivo es dilucidar una de las tomas de posición presente en esta obra literaria, específicamente, la toma de posición romántica en relación con sus personajes femeninos y los valores socio-económicos de la modernidad y el capitalismo, para establecer su impacto en el campo literario colombiano. El análisis textual se encuentra ordenado a partir de los conceptos de posición romántica (Girard, 1963), cronotopo (Bajtín, 1986: 269) héroe novelesco (Lukács, 1974: 161-162) y sistema de personajes como ejes fundamentales en los que se despliega buena parte de la axiología de la novela.

\section{Palabras clave}

Héroe novelesco, toma de posición romántica, amor romántico, toma de posición desesperanzada, deber ser social, cronotopo de la novela del idilio y personajes femeninos.

\section{Abstract}

This essay is a sociocritic analysis of the novel La vorágine (1924), written by José Eustasio Rivera (Neiva, 1888-New York, 1928). Its objective is to elucidate one of the existent axiological position presented in this literary work, specifically, the romantic one (Girard, 1963). The reading of the text is organized in two parts: first, the idealization of love, where it is established the construction of the romantic position taken in terms of love, the socioeconomic values of modernity and capitalism, taking into account the hero of the novel and the idealization of a woman, according to the women characters and their ideological voice.

\section{Keywords}

Fabulous hero, romantic axiological position, romantic love and unhopeful axiological position, social duty, chronotopo of the idyllic novel and female characters.

Artículo recibido el 6 de marzo de 2008 y aprobado el 14 de noviembre de 2008.

* Profesional en Lingüística y Literatura de la Universidad de Cartagena (2001), Magíster en Literatura Hispanoamericana del Instituto Caro y Cuervo (2007) y profesor de la Universidad Pedagógica Nacional. Correo electrónico: cortiz@pedagogica.edu.co 
[...] Hoy, como nunca, siento nostalgia de la mujer ideal y pura, cuyos brazos brinden serenidad para la inquietud, frescura para el ardor, olvido para los vicios y las pasiones. Hoy, como nunca, añoro lo que perdí en tantas doncellas ilusionadas, que me miraron con simpatía y que en el secreto de su pudor halagaron la idea de hacerme feliz ${ }^{1}$.

Arturo Cova. La vorágine.

Entre la publicación de María (1867) y la de $L a$ vorágine (1924) hay poco menos de sesenta años, la distancia suficiente para que las letras nacionales se resarcieran de la retórica romántica ${ }^{2}$ que instaurara la novela de Isaacs e iniciara la búsqueda de otra forma de escritura, cuyas temáticas estuvieran más acorde con los avatares del ser contemporáneo y su entorno.

La vorágine de José Eustasio Rivera se exhibe antagónica al Romanticismo literario que modeló la literatura colombiana de la segunda mitad del siglo XIX y principios del siglo XX. No obstante, la novela elabora una toma de posición romántica como manifestación de la búsqueda del héroe por hallar valores auténticos en un mundo degradado (Lukács, 1974: 161-162). Además, ésta representa un cuestionamiento de la ética social colombiana, en la medida que estructura sus discursos mediante la crítica de un ethos concreto: el comportamiento de la mujer en la sociedad colombiana de la segunda década del siglo XX. Cuestionamiento que se evidencia en la reevaluación social e individual del sujeto femenino como resultado de la incursión de las ideas modernas en el país. La idealización del

1 Rivera, 2001: 204. Todas las citas siguientes procederán de esta edición.

2 Compréndase la retórica romántica como una elaboración estética o forma de expresión en que se soporta el movimiento romántico que dominó las artes europeas desde finales del siglo XVIII hasta mediados del siglo XIX. Esta retórica está caracterizada por ciertos elementos como la entrega a la imaginación y la subjetividad, el culto al individuo (libertad de pensamiento y expresión) y su idealización de la naturaleza. Asimismo, se destacan, entre otros puntos, la exaltación de los sentimientos, una tendencia al frenesí, a la melancolía, al hastío del mundo, la nostalgia por el pasado, la autodestrucción y la introducción del elemento grotesco en el arte. En esta retórica romántica también están inscritos algunos temas románticos como el anarquismo, la política y los temas sociales. De este modo, se explica que el desencanto generalizado de los románticos con la organización social se plasmó a menudo en la crítica concreta de la sociedad urbana. amor y la mujer en La vorágine señala los linderos de esta lectura crítica; a partir de estos ejes temáticos se accede al nivel discursivo del héroe y de todos los personajes femeninos que sostienen gran parte de la significación de la novela.

\section{La idealización del amor}

Desde su apertura, la narración de La vorágine está determinada por una actitud desencantada ${ }^{3}$. Esta actitud tiene sus bases en una toma de posición novelesca, abordada desde la perspectiva de René Girard (1963); es decir, la novela en su inicio se erige en el anhelo y el deseo consciente de alcanzar un ideal lejano o irrealizable: el amor.

Girard define la posición novelesca a partir de la diferenciación que establece entre ésta y la toma de posición romántica. Él parte de la idea de que el "espíritu romántico" reside en ciertas novelas 4 caracterizadas por un héroe que dispone su vida a partir de unas ilusiones y unos ideales que toma por valores absolutos, razón por la que entra en un permanente conflicto con su entorno. Todos los personajes que asumen esta postura se sumergen en una mentira romántica, que sólo es abandonada al final de la narración cuando logran alcanzar la lucidez y se reconcilian con la razón del mundo. En esas circunstancias, el "espíritu romántico" es una condición previa de la construcción novelesca de algunas obras literarias. Este "espíritu romántico" en la literatura se percibe a partir de la relación triangular entre un sujeto, su deseo y un objeto deseado. Según esta propuesta, existen dos formas en las que un héroe puede desarrollar esta "enfermedad metafísica”, como la llama Girard, y es por medio del deseo. Primero, a partir de un deseo según el otro, cuya característica esencial es la conciencia de quién desea. Es el caso del Quijote, que desea a

3 De acuerdo con Álvaro Mutis (1998: 288), esta actitud es determinante para la elaboración de una toma de posición desesperanzada. La vorágine es una novela que opta por una toma de posición desesperanzada, que tiene su origen en una toma de posición romántica. Valga aclarar que en este análisis sólo nos ocuparemos de la romántica.

4 René Girard ejemplifica con novelas como: Don Quijote de la Mancha (1605-1615), Rojo y negro (1830), Madame Bovary (1857) y Por el camino de Swann (1913), entre otras. 
partir de las ambiciones de Amadís de Gaula, y en el caso especial de La vorágine, Arturo Cova, que desea a partir de las ambiciones (ethos amoroso) de los poetas románticos. El segundo es un deseo según "yo", "de cuya posesión se vanagloria la mayor parte de nosotros" (Girard, 1963: 8).

Cabe anotar que, cuando esta "aritmética del deseo", por llamarla de algún modo, es fracturada por la conciencia del héroe, se tiene una formula con características novelescas 5 , pues se revela la presencia de un mediador entre un sujeto y un objeto del deseo, es decir, el individuo que desea está plenamente consciente de su deseo. Es justamente desde este último término que versa el siguiente análisis.

En La vorágine, esta relación triangular se evidencia cuando se plantea la búsqueda del "don divino del amor ideal" como finalidad básica de su personaje-narrador, Arturo Cova, que empieza su manuscrito de la siguiente manera:

Antes de que me hubiera apasionado por mujer alguna, jugué mi corazón al azar y me lo ganó la violencia. Nada supe de los deliquios embriagadores, de la confidencia sentimental, ni de la zozobra de las miradas cobardes. Más que enamorado, fui siempre el dominador cuyos labios no conocieron suplicas. Con todo, ambicionaba el don divino del amor ideal, que me encendiera espiritualmente, para que mi alma destellara en mi cuerpo como la llama en el leño que alimenta.

Cuando los ojos de Alicia me trajeron la desventura, había renunciado ya a la esperanza de sentir un afecto puro. En vano mis brazos -tediosos de libertad- se tendieron ante muchas mujeres implorando para ellos una cadena. Nadie adivinaba mi ensueño. Seguía el silencio en mi corazón (p. 9).

Arturo Cova señala de entrada el ideal que persigue ciegamente. Él es un poeta romántico que se halla en busca del amor ideal, por ende, de la mujer que lo encarne. Ideal que a pesar de su basta experiencia de seductor siempre le es esquivo, por lo que el personaje ha empezado a reconoce su derrota

5 El término novelesco propuesto por Girard (1963: 17), aquí lo llamaremos toma de posición novelesca. y, por supuesto, a flaquear en su búsqueda. Lo que significa que el protagonista de La vorágine, desde su inicio, ha empezado a rechazar esa mentira romántica que resulta insuficiente para comprender el mundo, dado que hay en él una postura consciente con respecto a la falsedad de su objeto deseado. Arturo Cova empieza de esta forma su cura contra el idealismo romántico.

Pero éste no es el único personaje que está tras la búsqueda del "don divino del amor ideal". Alicia, su amante, también lo pretende; de hecho, huye con Arturo guardando la esperanza de hallar ese afecto en sus brazos. Las siguientes palabras así lo registran:

Alicia fue un amorío fácil: se me entregó sin vacilaciones, esperanzada en el amor que buscaba en mí. Ni siquiera pensó casarse conmigo en aquellos días en que sus parientes fraguaron la conspiración de su matrimonio, patrocinados por el cura y resueltos a someterme por la fuerza. Ella me denunció los planes arteros. Yo moriré sola, decía: mi desgracia se opone a tu porvenir.

Luego cuando la arrojaron del seno de su familia y el juez le declaró a mi abogado que me hundiría en la cárcel, le dije una noche, en su escondite, resueltamente: ¿Cómo podría desampararte? ¡Huyamos! Toma mi suerte, pero dame el amor.

¡Y huimos! (p. 9).

La fuga de dos jóvenes de buena familia en una sociedad conservadora representa un acto de franca expresión romántica, pues, en este hecho se ha dado prioridad a los sentimientos $y$, ante todo, a los intereses individuales sobre las convenciones sociales.

El amor es el objeto deseado, su búsqueda es el leitmotiv de todas las acciones de La vorágine. Pese a ello, es claro que el ideal del amor que aparece retratado en la novela no coincide con el ideal caballeresco ni con el de la poesía romántica; ese amor caracterizado por la "tendencia a resaltar la primacía del sentimiento sobre el pensamiento y de la intuición sobre el concepto" (Pérez-Rioja, 1983: 261). El amor que se muestra en la novela tiene características de una pasión contradictoria, llena de altibajos que se torna por momentos incomprensible; es, en principio, un amor práctico que se acerca mucho 
más a la pasión carnal, ilusoria y efímera, que a ese afecto excelso y glorioso que describen los poetas románticos. Por esta razón, Arturo Cova describe así sus afectos por Alicia:

Respecto de Alicia, el más grave problema lo llevo yo, que sin estar enamorado vivo como si lo estuviera, supliendo mi hidalguía lo que no puede dar mi ternura, con la convicción íntima de que mi idiosincrasia caballeresca me empujará hasta el sacrificio, por una dama que no es la mía, por un amor que no conozco (p. 21).

Esa relación que Arturo Cova mantiene con Alicia es bastante contradictoria, pues, a pesar de dejar claro que con ella tampoco encontró el amor, sino la desventura, nunca la desampara. De hecho, él siempre está tratando de justificar su lealtad a la muchacha y de buscar un motivo para permanecer a su lado, tanto que desarrolla una dependencia emocional por la joven. Por ejemplo, se vuelve posesivo y celoso, a tal punto que no admite que nadie, en especial Narciso Barrera, se acerque a ella. La idea de verlos juntos, lo sumerge en el más tormentoso de los pensamientos y las bajas pasiones. De la misma manera, él es conciente de que Alicia no lo ama, que se "lanzó a sus brazos", buscando la liberación de un matrimonio arreglado con un viejo terrateniente.

El amor que se presenta en La vorágine es la anticipación de la degradación de los valores tradicionales, pues Arturo Cova y Alicia se alejan de su "deber ser moral" (Lipovestsky, 1994) para entregarse a la realización de un deber ser individual: encontrar el verdadero amor, ya sea juntos o por separado ${ }^{6}$. No obstante, cada uno de los personajes tiene unas prioridades profesionales y económicas que yuxtapone a sus ideales románticos. Por ejemplo, él es un personaje que se debate entre el amor y las ideas de riquezas y progreso:

6 Bajtín (1986), en el estudio que realiza del cronotopo de la novela del idilio, en las novelas del período moderno, llama la atención sobre la manera en que se recrea este concepto en una línea novelística representada por Stendhal, Balzac y Flaubert. Explica el autor que: “Aquí se trata, ante todo, del hundimiento y la transformación de la ideología y la psicología idílicas, no adecuadas al nuevo mundo capitalista" (Bajtín, 1986: 269). Por consiguiente, ya no asistimos a la sublimación filosófica del idilio, sino, más bien, al derrumbamiento de ciertos valores como el amor, la familia y la amistad.
El pensamiento de riqueza se convirtió en esos días en mi dominante obsesión, y llegó a sugestionarme con tal poder, que ya me creía ricacho fastuoso, venido a los llanos para dar impulso a la actividad financiera (p. 40).

Es así que la experiencia romántica se deforma con la lucidez que ha adquirido Arturo Cova, quien se aparta por momentos de su anhelo romántico para meditar sobre su situación real. Además, él también flaquea en su anhelo romántico porque es consciente que la realidad se contrapone a sus ideales, sabe en su aflicción que Alicia no pasa de ser un "un amorío fácil"; sin embargo, su condición de caballero, su origen burgués y su talante de poeta romántico le exigen enmendar su falta, y por esa razón no la abandona. Es un personaje escindido entre sus ideales individuales y la naturaleza de su conducta. De ahí justamente que fluctúe en dos posturas criticas, que vaya y venga del romanticismo a la desesperanza y viceversa, por ello, siempre se le encuentra reflexionando en torno a su vida de aventuras y amores pasajeros, como queda expuesto en el siguiente aparte de la novela:

Fama de rendido galán gané en el ánimo de muchas mujeres, gracias a la costumbre de fingir, para que mi alma se sienta menos sola. Por todas partes fui buscando en qué distraer mi inconformidad, e iba de buena fe, anheloso de renovar mi vida y de rescatarme a la perversión; pero dondequiera que puse mi esperanza hallé lamentable vacío, embellecido por la fantasía y repudiado por el desencanto. Y así, engañándome con mi propia verdad, logré conocer todas las pasiones y sufro su hastío, y prosigo desorientado, caricatureando el ideal para sugestionarme con el pensamiento de que estoy cercano a la redención. La quimera que persigo es humana, y bien sé que de ella parten los caminos para el triunfo, para el bienestar y para el amor. Mas han pasado los días y se va marchitando mi juventud sin que mi ilusión reconozca su derrotero; $y$ viviendo entre mujeres sencillas, no he encontrado la sencillez, ni entre las enamoradas el amor, ni la fe entre las creyentes. Mi corazón es como una roca cubierta de musgo, donde nunca falta una lágrima. ¡Hoy me ha visto usted llorar, no por flaqueza de ánimo, que bastante rencor le 
tengo a la vida; lloré por mis aspiraciones engañadas, por mis ensueños desvanecidos, por lo que no fui, por lo que ya no seré jamás! (p. 21).

Arturo Cova se lamenta al descubrir que el ideal que anduvo buscando es una completa falacia. Él no es totalmente consciente de que el problema reside en la manera en que se ha acercado a las mujeres para conseguir su anhelo. Él ha corroído el amor, lo ha degradado al estricto juego de goce y placer físico, o lo ha contaminado con sus vicios de mujeriego. Por ello, cuando se relaciona con las mujeres con el fin de bañarse de su candor, su fe religiosa y su amor, no logra recibir nada distinto al reflejo de sus propios excesos que lo sumen en el desencanto. Como quien dice, anda por la vida buscando un valor autentico de un modo inicuo.

En otras palabras, el amor que aparece expuesto en La vorágine ha empezado a revaluarse. Este sentimiento, ante todo, se soporta en las circunstancias de la realidad sociocultural abordada sin tapujos, en una realidad contradictoria y problemática como es la insipiente sociedad moderna, en la que los valores éticos que regían a la familia, como el amor y la fraternidad, han sido desplazados por una ética de bienestar individual y los derechos subjetivos. Arturo Cova se cura de su mentira romántica al descubrir que su realidad está muy lejos de parecerse a su ideal estético y ético, se desencanta del mundo porque éste es totalmente opuesto al lugar que creía que era, por esta razón, termina repudiando a la selva:

¿Cuál es aquí la poesía de los retiros, dónde están las mariposas que parecen flores traslúcidas, los pájaros mágicos, el arroyo cantor? ¡Pobre fantasía de los poetas que sólo conocen las soledades domesticadas!

¡Nada de ruiseñores enamorados, nada de jardín versallesco, nada de panoramas sentimentales! Aquí, los responsos de sapos hidrópicos, las malezas de cerros misántropos, los rebalses de caños podridos. Aquí, la parásita afrodisíaca que llena el suelo de abejas muertas; la diversidad de flores inmundas que se contraen en sexuales palpitaciones y su olor pegajoso emborracha como una droga; la liana maligna cuya pelusa enceguece los animales; la pringamosa que inflama la piel, la pepa del curujú que parece irisado globo y sólo contiene ceniza cáustica, la uva purgante, el corozo amargo (p. 160).

Es a partir de este momento que la novela de Rivera entra en la verdad novelesca que explica Girad. El amor en La vorágine es el deseo-elucubración de un afecto inmaculado, razón por la que es imposible obtenerlo. Arturo Cova busca el amor en el lirismo de la poesía, pero se topa con la realidad, es decir, un proceder machista que ha mancillado el objeto de su deseo, degradándolo a un sentimiento lleno de vicios y prejuicios que lo alejan de esa sensación hecha de palabras y gestos envanecidos del que hablan los libros. Al final, el protagonista se hace consciente de la cruda realidad de la vida y acepta su destino, se doblega ante él; es decir, abandona la búsqueda del amor y la mujer ideal, y empieza a luchar por Alicia, la mujer que le deparó el destino.

\section{La idealización de la mujer}

Esta significación que adquiere el amor en La vorágine tiene como trasfondo la desmitificación de la familia, tal como se muestra en el caso de Alicia, quien desobedece a sus padres por rehusarse al matrimonio convenido por ellos. Asimismo, otros personajes femeninos de la novela reinciden en este hecho, como es el caso de María Gertrudis (hija de Clemente Silva), quien deshonra a su hogar al entregarse a su novio y fugarse con él, días antes de la boda. A continuación, las palabras de su padre sobre este incidente:

-Para poder contarles mi historia -nos dijo esa tarde- tendría que perder el pudor de mis desventuras. En el fondo de cada alma hay algún episodio íntimo que constituye su vergüenza. El mío es una mácula de familia: ¡mi hija María Gertrudis dio su brazo a torcer! (p. 127).

Los ejemplos anteriores son indicios de que la familia figura en la novela como un bien trascendental que empieza a ser desgastado por los personajes femeninos, pues, según las costumbres socioculturales, sobre ellas recaía el peso de sostener la moral y la honradez de esta institución (Lipovetsky, 1999). 
De esta forma, Alicia, Griselda, Clarita, María Gertrudis y Zoraida Ayram conforman representaciones fuertemente estructuradas que se oponen al esquema conservador de la mujer. Sus actos son expuestos como responsables de la corrosión de la familia, una institución que, según la novela, amerita ser honrada y respetada, como lo dejan entender las desgarradoras palabras de Clemente Silva por la desintegración de su hogar a causa de una ignominia.

Arturo Cova, como personaje-narrador, es quien construye la imagen de los personajes femeninos, con quien su contacto ha sido más directo. Influido por los diversos estados de ánimo por los que atraviesa en su huida al llano y por un ideal incuestionable del amor y la mujer ideal, este personaje tiene una percepción no muy positiva de las mujeres con quienes se topa a lo largo de su camino. En su criterio, los personajes femeninos de la novela, más que incurrir en faltas contra la moral y las buenas costumbres, infringen el prototipo romántico de mujer, es decir, no encarnan el ideal del amor; peor aún, se hallan lejos de "las virtudes para ser la esposa ideal del que nos habla el Evangelio" (p. 180).

Tomasita Pérez Hernández (1987), en un estudio titulado La mujer en la literatura colombiana de la segunda mitad del siglo XIX, expone la visualización de la mujer ante la sociedad colombiana de este periodo, específicamente el modo en que la literatura de esta época construye una imagen femenina a partir de la moral cristiana. Basada en su investigación concluye que novelas como María, Manuela, Frutos de mi tierra y Tránsito convergen en este ideal femenino, pues las mujeres de estas historias responden a un patrón de conducta que da cuenta de una sociedad conservadora. En otras palabras, son mujeres cuyas actividades y oficios no pasaban de ser domésticas. Por ello, expresa que:

En el estudio que nos ocupa acerca de la condición social de la mujer vemos retratada en todas las novelas leídas, en mayor o menor medida, esa imagen de la mujer recatada piadosa y hogareña, más persistente en la mentalidad de aquella clase dirigente provincial y conservadora, cuya normatividad es defendida ante el peligro que puede significar las reformas liberales de medio siglo. Es importante observar que esta imagen es la que se va proyectando en las diferentes esferas de la sociedad, sin distingos políticos, económicos, raciales, etc., y cuyo catalizador más poderoso es la autoridad de la Iglesia que, arraigada desde la vida colonial, se levanta imponente a lo largo del siglo XIX como una fortaleza infranqueable que defiende a la sociedad de las arremetidas modernizantes y secularizadoras atentatorias del orden y la estabilidad; actitud históricamente comprensible desde su óptica (1987: 46-47).

La vorágine, aunque pertenece a un periodo posterior, es una de las primeras novelas colombianas en las que se empieza a dar un rompimiento con ese papel femenino sumiso o dependiente. Las mujeres de la novela, pese a no exceder las labores caseras y el papel reproductor, abandonan su proceder dócil y pasivo7. Ninguna de estas mujeres construidas por Rivera está encaja en el prototipo femenino que idealizó el romanticismo del siglo XIX, es decir, de la mujer casta, tímida y pudorosa, que encarnaba los personajes en la novela María. Por ejemplo, Alicia es presentada como una joven de ciudad de buena familia, inteligente. Ella se presenta rebelde, con actitud sumamente práctica, con un proceder libre y autónomo, y con clara conciencia de la desventaja que tiene ser mujer para la sociedad de principios de siglo XX. La siguiente es su historia:

El pensamiento de que la infeliz se creyera desamparada me movió a tristeza, porque ya me había revelado el origen de su fracaso. Querían casarla con un viejo terrateniente en los días que me conoció. Ella se había enamorado, cuando impúber, de un primo suyo, paliducho y enclenque,

7 Se puede asegurar, entonces, que los esquemas de la moral tradicional han sido vulnerados por los intereses individuales que devienen del cambio de siglo con la irrupción de las primeras ideas modernas en América Latina. Se parte del hecho que Kant designa la modernidad como "la mayoría de edad del hombre", definida a partir de su autonomía de pensamiento. De acuerdo con el filósofo alemán, las ideas de ilustración surgen de un deseo de reexaminar y cuestionar las ideas y los valores recibidos por la moral eclesiástica, de explorar nuevas ideas en direcciones muy diferentes a las fuentes autorizadas, como Aristóteles y la Biblia. Su premisa revela una ruptura con una estructura social que inhibe el desarrollo libre del sujeto, que le impide hacer uso de su propia racionalidad. En ese sentido, más que un conjunto de ideas fijas, la Ilustración implicaba una actitud, un método de pensamiento. 
con quien estaba en secreto comprometida; luego aparecí yo, y alarmado el vejete por el riesgo de que le birlara la prenda, multiplicó las cuantiosas dádivas y estrechó, el asedio, ayudado por la parentela entusiástica. Entonces Alicia, buscando la liberación, se lanzó a mis brazos (p. 11).

Ella representa, asimismo, el motor del acontecimiento que pone en marcha la narración, la fuga de Bogotá. Ese comportamiento que escandaliza a su familia y a la sociedad determina en ella el deseo de tomar las riendas de su propio destino. Por esa razón, al sentirse traicionada por Arturo Cova se va para la selva con Griselda y Narciso Barrera.

Alicia es el primer personaje que se opone al destino de Arturo Cova, antes que ningún otro. Así lo siente él, pues, la mayoría de las veces, la ve como un obstáculo que le impide realizarse como individuo. "Pero Alicia me estorbaba como un grillete, ¡Si al menos fuera más arriscada, menos bisoña, más ágil!” (p. 10). Sumado a esto, Arturo siente que ella no es el amor que buscaba, sino el que tuvo que padecer. Por esta razón, la relación de estos personajes se soporta en un fuerte antagonismo desde el inicio de la novela. Con el personaje de Alicia se crea una desestabilización significativa en la historia, pues está a cargo de cuestionar y desmitificar toda ética presente en la sociedad colombiana de la época. Cabe anotar que una construcción literaria de esta índole tenía el propósito o el peso de establecer unos parámetros moralizantes o un deber-ser social en una obra artística, labor que en esta novela no se lleva a cabo y se impone un no deber-ser social (Lipovestsky, 1994).

Por otro lado, está la niña Griselda, que es otra construcción femenina con un carácter fuerte, pero con una actitud sumamente ambigua. Este personaje se podría describir como una mujer que defiende su honra con tanto ímpetu que asesina a su agresor: un capitán del ejército. De ahí que el pasado la persiga, no como tormentosos recuerdos, sino con la inconformidad y el sacrificio de quien le tendió la mano, "su hombre Fidel Franco", que asume la culpa para salvarla. La siguiente son las palabras de Griselda que se confiesa ante Cova buscando un poco de redención:
¡He sufrío tanto! ¡Imagina lo que fue pa’ mí tenderlo al pie de mi honra! ¡Y dejé que Fidel se lo echara encima pa' salvarme, pa' defenderme! Y luego, el suplicio de ver a mi hombre, triste, desamorao, arrepentío, dejándome sola en La Maporita días y semanas; pa' no mirarme, pa' no tené que darme la mano, repitiéndome que deseaba largarse lejos, a otros países, onde nadie supiera lo suceío y no tuviera que tar de peón jugándose la vida con las toráas (p. 216).

Este es el trasfondo del personaje, sin embargo, lo que narra al principio Arturo Cova es totalmente diferente. Para él, Griselda no pasa de ser una hembra para distraerse, con la que se puede flirtear mientras soluciona su situación con su mujer. Comportamiento que es entendido por el caballero como de una mujer vulgar y sin vergüenza, muy alejada de las señoritas de la capital como Alicia. No obstante, este personaje es la representación de una mujer extrovertida que no parece medir las consecuencias de sus coqueteos porque, muy por encima de sus juegos, siempre sale a relucir la lealtad a su esposo Franco, de ahí justamente su ambigüedad.

A Clarita, la muchacha que ayuda a Arturo cuando está de paso por la hacienda del viejo Zubieta, la acoge una tragedia no muy diferente a la anterior, al huir de su casa cae en un destino indecoroso que la agravia y la esclaviza:

En estas fundaciones me dejó botada el coronel Infante, guerrillero venezolano que tomó a Caicara. Ayí me rifaron al tresiyo, como simple cosa, y fui ganada por un tal Puentes, pero Infante me descontó al liquidar el juego. Después lo derrotaron, tuvo que asilarse en Colombia y me abandonó por aquí (p. 57).

Cova, en un pasaje de la novela, utiliza las siguientes frases para referirse a ella: "escoria de lupanar", "sobra del bajo placer", "loba ambulante y famélica”. Tanto Griselda como Clarita tienen ese aire de ser mujeres precipitadas, irreflexivas, impetuosas, chabacanas, agrestes o simplemente vulgares e ignorantes; esa es la idea que se percibe de las descripciones del narrador cuando trata de encasillarlas como mujeres del campo que, además, han faltado a la honra de sus familias. 
Por último, en un papel que se puede equiparar con Alicia por su fuerza de carácter, está el personaje de Zoraida Ayram, también conocida como "la turca" o "la madona". Ella constituye uno de los antagonismos femeninos más impetuosos, no sólo por oponerse a Arturo Cova, sino, especialmente, por transgredir al extremo el papel que tradicionalmente se reservaba para estos personajes femeninos; ya que no sólo rechaza el matrimonio que le ofrece Lucianito, el hijo perdido de Clemente Silva, sino que también ostenta poder económico, el cual le permite gozar de los beneficios de la libertad e igualdad de género como cualquier hombre dueño de una cauchería. Eso sin mencionar que se vale de su cuerpo para obtener ventaja de sus negocios (comerciar y traficar caucho). Así la percibe Cova:

[...] ¡Otra vez, como en las ciudades, la hembra bestial y calculadora, sedienta de provechos, me vendía su tentación!

Observándola de reojo, comencé a sentir la agresividad que precede a los desafíos. ¡Mujer singular, mujer ambiciosa, mujer varonil! Por los ríos más solitarios, por las correntadas más peligrosas, atrevía su batelón en busca de los caucheros, para cambiarles por baratijas la goma robada, exponiéndose a las violencias de toda suerte, a la traición de sus propios bogas, al fusil de los salteadores, deseosas de acumular centavo a centavo la fortuna con que soñaba, ayudándose con su cuerpo cuando el buen éxito del negocio lo requería. Por hechizar a los hombres selváticos ataviábase con grande esmero, y al desembarcar en los barrancones, limpia, olorosa, confiaba la defensa de sus haberes a su prometedora sensualidad (p. 181).

Ella es la imagen-reflejo de la ruptura o la insubordinación, que junto con las anteriores caracterizaciones, conforman las anti-heroínas que transgreden las leyes de su sociedad. Respecto al tema de los personajes femeninos en la literatura, Lucía Guerra-Cunningham (1986) considera que,

[...] El personaje literario se elabora básicamente a partir de un código de la ficción y de los valores dominantes del grupo que realiza la producción cultural, la mujer en el texto literario ha funcio- nado como un signo portador de los valores y modos de conducta atribuidos al sexo femenino en la estaticidad de su rol primario de madre y esposa. Por tanto, al nivel consciente de las relaciones sociales que reiteran la reproducción biológica como núcleo generador, el personaje literario femenino es fijado a partir de un deberser como sinónimo de la pasividad, la inocencia y la subordinación, atributos que poseen como fuente primaria la figura maternal de la Virgen María. Concepto ético-social que se repite en su estructura ejemplificadora en un no-deber-ser representado por las imágenes deleznables de la pecadora, la bruja, la mujer fatal (1986: 8).

La vorágine enmarca el papel de la mujer en un esquema activo, decidido y autónomo; a partir de lo cual el autor resalta las desventajas que esto conlleva. Por ejemplo, la corrupción de la familia y los valores morales son desplazados por el bienestar individual o económico. Es así como la obra de Rivera cuestiona el papel altivo de la mujer en la modernidad, expresado en los personajes femeninos de Alicia, Griselda, Zoraida y Clarita, quienes establecen una ruptura con la tradición, al no estar completamente sometidas a los valores y las imposiciones masculinas, signo de una axiología conservadora:

Quejosa de la suerte, agravaría su decepción al pensar en tantas mujeres nacidas en la abundancia, en el lujo, en la ociosidad, que juegan con su virtud por tener en qué distraerse, y que aunque la pierdan siguen con honra, porque el dinero es otra virtud (p. 182).

Estas son las palabras de Cova elucubrando sobre los orígenes de Zoraida Ayram. Este apartado presenta el poder del dinero como un valor significativo de la modernidad capitalista, pues permite comprar cualquier cosa, hasta la virtud u honra de una mujer. Este es uno de los valores que degrada y se impone sobre la ética por la que se venía rigiendo la sociedad.

La dimensión axiológica de La vorágine empieza a esclarecerse gracias a las transformaciones sociales que cuestiona Arturo Cova, éstas han desplazado la significación de unos principios éticos por un notable desequilibrio entre el hombre y el mundo. 
Por ejemplo, el romanticismo que la novela critica es manejado por este personaje-narrador, quien reflexiona en torno a la búsqueda de valores como el amor ideal, la familia y sus afectos en una actitud desencantada. Con lo anterior, La vorágine no sólo muestra una ruptura con el canon literario, sino también con los esquemas sociales perpetuados del siglo XIX. De ahí justamente que la novela de Rivera toma la mujer como un mal necesario, un ser al que siempre se está cuestionando por su comportamiento, o se está repudiando por infringir las normas.

Esta revaloración del papel femenino en la sociedad que refleja la novela de Rivera tiende a develar dos cosas: primero, la marcada misoginia producto de la crítica severa que el autor hace a la mujer colombiana en las primeras décadas del siglo $\mathrm{XX}$ y, por otra parte, una construcción de personajes complejos, muy aterrizados en los conflictos socioculturales de la época, lo que los distancia de un mundo ideal alejados de la categoría maniqueísta de bueno-malo y, sobre todo, los hace impredecibles. Zoraida Ayram, por ejemplo, a pesar de su carácter fuerte y su despotismo, sucumbe ante el amor de Arturo Cova y Lucianito. Esta última característica es justamente lo que permite al personaje principal una reconciliación con los personajes femeninos de la historia, ya que cuando conoce su desgracia, le es más fácil comprenderlos y aceptarlos. Reconoce que ante todo son mujeres que, en la mayoría de los casos, no tuvieron elección y, aún más, que existe algo en ellas que las une a su ideal. Esto dirá de Alicia antes de rescatarla de las caucherías:
¡Esa varona es buena y yo la perdí! ¡Yo la salvaré! ¡No me reproches este propósito, este anhelo, esta decisión! No tomes a mal que sea mi querida; hoy es sólo una madre en espera de su propio milagro. ¡Tantos en el mundo se resignan a convivir con una mujer que no es la soñada y, sin embargo, es la consentida, porque la maternidad la santificó! ¡Piensa que Alicia no ha delinquido, y que yo, despechado, la denigré! ¡Ven, sobre el cadáver de mi rival habrás de vernos reconciliados! Vamos a buscarla a Yaguanarí. Nadie la compra porque está encinta. ¡Desde el vientre materno mi hijo la ampara! (p. 220).

La espera de un hijo (Alicia), como la defensa de la honra en peligro (Griselda) y el sucumbir ante las emociones del amor (Zoraida Ayram) son las razones que presenta Arturo Cova para revindicar o devolverle la virtud a las mujeres de la novela. Él no cierra su manuscrito sin antes pagar esa deuda, justificando a las mujeres en algunos casos, y tratando de comprenderlas, en otros.

Más allá de las justificaciones, el personaje-narrador quiere dar a entender que no busca ya un ideal del amor y la mujer como siempre pregonó. Pareciera querer dar a entender que su dolor se debe a que no puede recuperar su propia inocencia, como lo explicita en el epígrafe que encabeza este escrito, la inocencia que perdió en la búsqueda de su idilio, en los brazos de tantas aventuras, de tantas decepciones, de tantas mujeres. 凤 


\section{Referencias bibliográficas}

Bajtín, M. (1984). Estética de la creación verbal. México: Siglo XXI Editores.

Bornay, E. (1993). Las hijas de Lilith. Madrid: Cátedra.

Cruz Kronfly, F. (1998). La tierra que atardece. Bogotá: Editorial Planeta.

Girard, R. (1963). Mentira romántica y verdad novelesca. Caracas: Ediciones Biblioteca Universidad Central de Venezuela.

Guerra-Cunningham, L. (1986). El personaje literario femenino y otras mutilaciones. En Hispamérica, 43, XV.

Gutiérrez, R. (1987). Locus terribilis. En V. Ordoñez, La vorágine textos críticos. Bogotá: Alianza.

Jaramillo et al. (1990). Literatura y cultura. La nación moderna. Identidad. Bogotá: Ministerio de Cultura.

Kant, E. (2002). Respuesta a la pregunta: ¿Qué es la ilustración? En Señal que cabalgamos, 5.

Lipovestky, G. (1994). La era del vacío. Barcelona: Anagrama.

Lipovetsky, G. (1996). El crepúsculo del deber. La ética indolora en los tiempos democráticos. Barcelona: Anagrama.

Lipovetsky, G. (1999). La tercera mujer: permanencia y revolución de lo femenino. Barcelona: Anagrama.
Lukács, G. (1974). Teoría de la novela. Buenos Aires: Ediciones Siglo Veinte.

Magnarelli, S. (1988). La "poetización" de los personajes femeninos en María y La vorágine. Revista de estudios colombianos, 5 .

Mutis, Á. (1998). La desesperanza y ¿Quién es Barnabooth? En Poesía y Prosa (p. 288). Bogotá: Colcultura.

Pérez Hernández, T. (1987). La mujer en la literatura colombiana de la segunda mitad del siglo XIX. Unimar, 12.

Pérez Rioja, J. A. (1983). El amor en la literatura. Madrid: Tecno.

Perus, F. (1998). De selvas y selváticos. Ficción autobiográfica y poética narrativa en Jorge Isaacs y José Eustasio Rivera. Bogotá: Plaza \& Janés Editores.

Rivera, J. E. (2001). La vorágine. Bogotá: Editorial Sol 90.

Rodríguez, I. (2003). Montañas con aroma de mujer: reflexiones posinsurgentes sobre el feminismo revolucionario. En S. Castro-Clareen, Narrativa femenina en América Latina. Prácticas y perspectivas teóricas. Iberoamericana, Vervuet. 